\title{
Effect of Mercerization and Benzoyl Peroxide Treatment on Morphology, Thermal Stability and Crystallinity of Sisal Fibers
}

\author{
Vijay K. Kaushik ${ }^{1, *}$, Anil Kumar ${ }^{1}$, Sus heel Kalia ${ }^{2}$ \\ ${ }^{1}$ Department of Chemistry, Hary ana Institute of Technology, Asodha, Bahadurgarh, 124507, Hary ana, India \\ ${ }^{2}$ Department of Chemistry, Shoolini University of Biotechnology and Management Sciences, Bajhol, 173 229, Dist. Solan (H.P.) India
}

\begin{abstract}
Studies on the use of natural fibers as replacement to man-made fiber in fiber-reinforced composites have increased and opened up further industrial possibilities. Natural fibers have the advantages of low density, low cost, and biodegradability. However, the main disadvantages of natural fibers in composites are the poor compatibility between fiber and matrix and the relative high mo isture sorption. Therefore, chemical treatments are considered in modify ing the fiber surface properties. In this study, Sisal fibers were modified using alkali and benzoyl peroxide solution of different concentration for different time intervals. Morphological changes, thermal stability and crystallinity of fibers were investigated using scanning electron microscope (SEM), TGA and XRD technique. Thermal stability of sisal fibers were decreased on mercerization. Whereas, sisal fibers treated with benzoyl peroxide the enhanced thermal stability. In case of XRD studies, sisal fibers show enhanced crystallin ity.
\end{abstract}

Keywords Sisal fiber, Benzoyl Peroxide, SEM, XRD, Crystallinity

\section{Introduction}

Effect of chemical treatments on surface morphology, thermal behavior and structure of natural fibers was reported by various authors[1-4]. Chemical treatments remove the lignin from surface of natural fibers and fiber surface becomes rough. Chemical treatments also reduce the number of free hydroxyl groups of the cellulose, which results in the reduction of the polarity of the cellulose molecules and enhance the compatibility with hydrophobic polymer matrices[5]. Alkaline treated sisal fibers were dipped in permanganate solution at concentrations of $0.033,0.0625$, and $0.125 \%$ in acetone for 1 minute[6]. As a result of permanganate treatment, the hydrophilic tendency of the fibers was reduced. Peroxide treatments include different concentration of benzoyl peroxide or dicumyl peroxide in acetone solution for about different minutes after alkali pretreatment[7-9]. Pre-treatments of the fiber can clean the fiber surface, chemically modify the surface, stop the moisture absorption process and increase the surface roughness[10]. As the natural fibers bear hydroxyl groups from cellulose and lignin, therefore, they are amenable to modification. The hydroxyl groups may be involved in the

* Corresponding author:

drkaushikvijay@gmail.com (Vijay K. Kaushik)

Published online at http://journal.sapub.org/textile

Copyright (C) 2012 Scientific \& Academic Publishing. All Rights Reserved hydrogen bonding within the cellulose molecules there by reducing the activity towards the matrix. Chemical modifications may activate these groups or can introduce new moieties that can effectively interlock with the matrix. Mercerization, isocyanate treatment, acrylation, permanganate treatment, acetylation, silane treatment and peroxide treatment with various coupling agents and other pre-treatments of natural fibers have achieved various levels of success in improving fiber strength[3]. The interest in using natural flax fibers as reinforcement in biocomposites has increased dramatically and also represents one of the most important uses.

Cellulosic fibers are hygroscopic in nature; moisture absorption can result in swelling of the fibers which may lead to micro-cracking of the composite and degradation of mechanical properties. This problem can be overcome by treating these fibers with suitable chemicals to decrease the hydroxyl groups which may be involved in the hydrogen bonding within the cellulose molecules. A number of fiber surface treatments like silane treatment, benzoylation and peroxide treatment were carried out which may result in improved mechanical performance of the fiber and composite[2,3]. The possibility of forming mechanical and chemical bonding at the fiber surface is mainly dependent on the surface morphology and chemical composition of the fibers. Therefore, the microscopic analys is of fiber surface topology and morphology is of utmost importance in fibrous composites 
In the present paper, we have reported the mercerization and peroxide treatments of sisal fibers using sodium hydroxide and benzoyl peroxide of different concentration and for different time interval. Effect of these treatments on morphology, crystallinity and thermal stability of sisal fibers is meagerly reported in literature.

\section{Experimental}

\subsection{Materials}

Sisal fibers were obtained from sisal research station, Bamra - Sarnbalpur, Orissa. Benzoyl peroxide, $\mathrm{NaOH}$ and acetone of $99.5 \%$ purity were supplied by S.D. Fine, India. Before chemical treatment sisal fiber were previously cut in definite size, washed with distill water and dried at $60^{\circ} \mathrm{C}$ followed by so xhlet extraction of sisal fibers with acetone for 72 hours and purified fibers were dried at roo $m$ temperature.

\subsection{Scanning Electron Microscopy (S EM)}

Scanning electron microscopic studies of sisal fibers and all its chemically treated fibers were carried out on Electron Microscopy Machine (LEO 435 VP, UK). Since cellulose has a non conducting behavior so it was gold plated to have an impact.

\subsection{Ther mo Gravi metric Analysis (TGA)}

Thermal analysis was carried out in nitrogen atmosphere at a heating rate of $10^{\circ} \mathrm{C} / \mathrm{min}$ by (Pyris Diamond) thermal analyzer (Perkin Elmer, USA) Nitrogen is supplied at a rate of $200 \mathrm{ml}$ per minute.

\subsection{X-Ray Diffr action (XRD) Studies}

$\mathrm{X}$-ray diffraction studies were performed under ambient condition on X-ray diffracto meter (D8 Advance, Brucker, AXS, Germany) using $\mathrm{Cu} \mathrm{K \alpha}(1.5418 \AA ̊)$ radiation, Ni filter and scintillation counter as $40 \mathrm{kV}$ and $30 \mathrm{~mA}$ on rotation between $5^{\circ}$ to $50^{\circ}$ at $2 \theta$ scale at 1 second step size. Percentage crystallinity and crystallinity index was calculated as followed

$$
\% C r=\frac{l_{22}}{l_{22}+l_{18}} \times 100 \quad \text { C.I. }=\frac{l_{22}-l_{18}}{l_{22}}
$$

Where $I_{22}$ and $I_{18}$ are the crystalline and amorphous intensities at $2 \theta$ scale close to $22^{\circ}$ and $18^{\circ}$, respectively.

\subsection{Alkali Treatment}

Sisal fiber were soaked in 5\%,10\% and 15\% (By Weight) solution of sodium hydroxide for $4 \mathrm{hr}$. at room temperature. After treat ment, fibers were thoroughly washed with distilled water and dried in hot air oven at $80^{\circ} \mathrm{C}$ for 24 hours. Reaction is shown in figure 1.

\subsection{Peroxide Treatment}

The peroxide treatment was carried out on an alkali pretreated sisal fiber using benzoyl peroxide at a fixed concentration for different time intervals, reaction shown in figure 2. Sisal fibers were treated with $5 \%$ benzoyl pero xide in acetone for 30 and 45 minutes. After treatments, fibers were thoroughly washed with distilled water and dried in hot air oven at $80^{\circ} \mathrm{C}$ for 24 hours

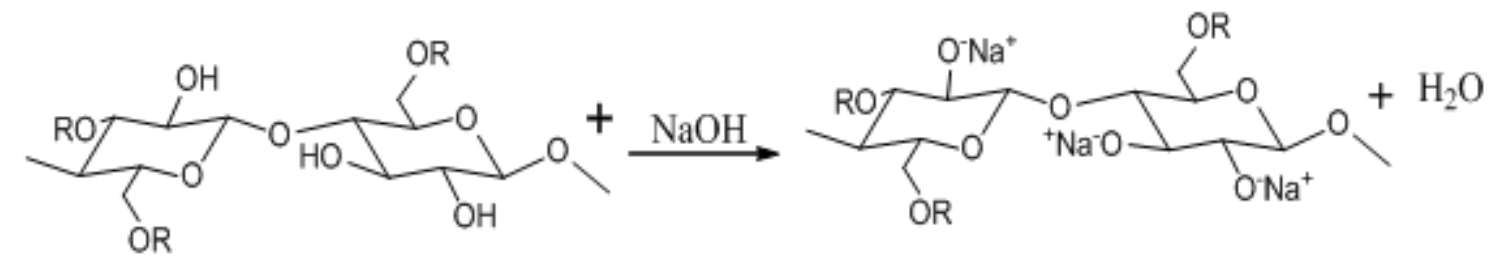

Cellulose

Mercerized cellulose

Figure 1. Reaction of cellulose fiber with $\mathrm{NaOH}$<smiles>CC(C)(C)C1(C)CCCCC1</smiles>

benzoyl peroxide

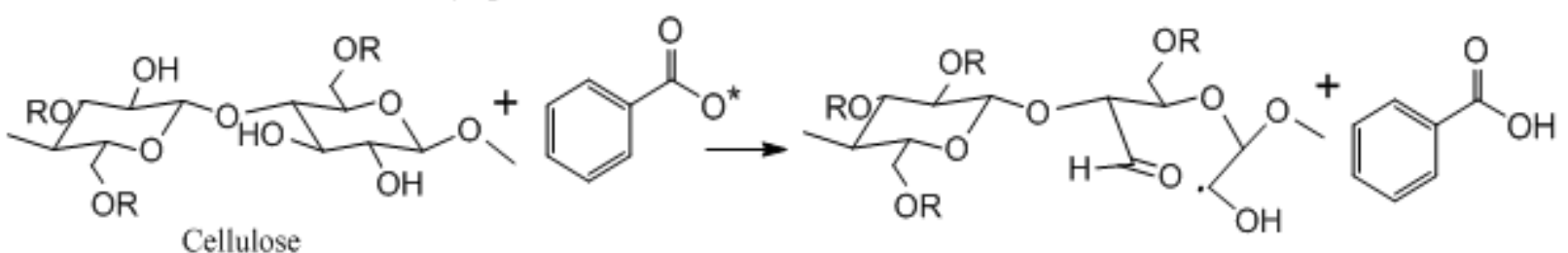

Figure 2. Showing reaction of Sisal fiber with benzoyl peroxide 

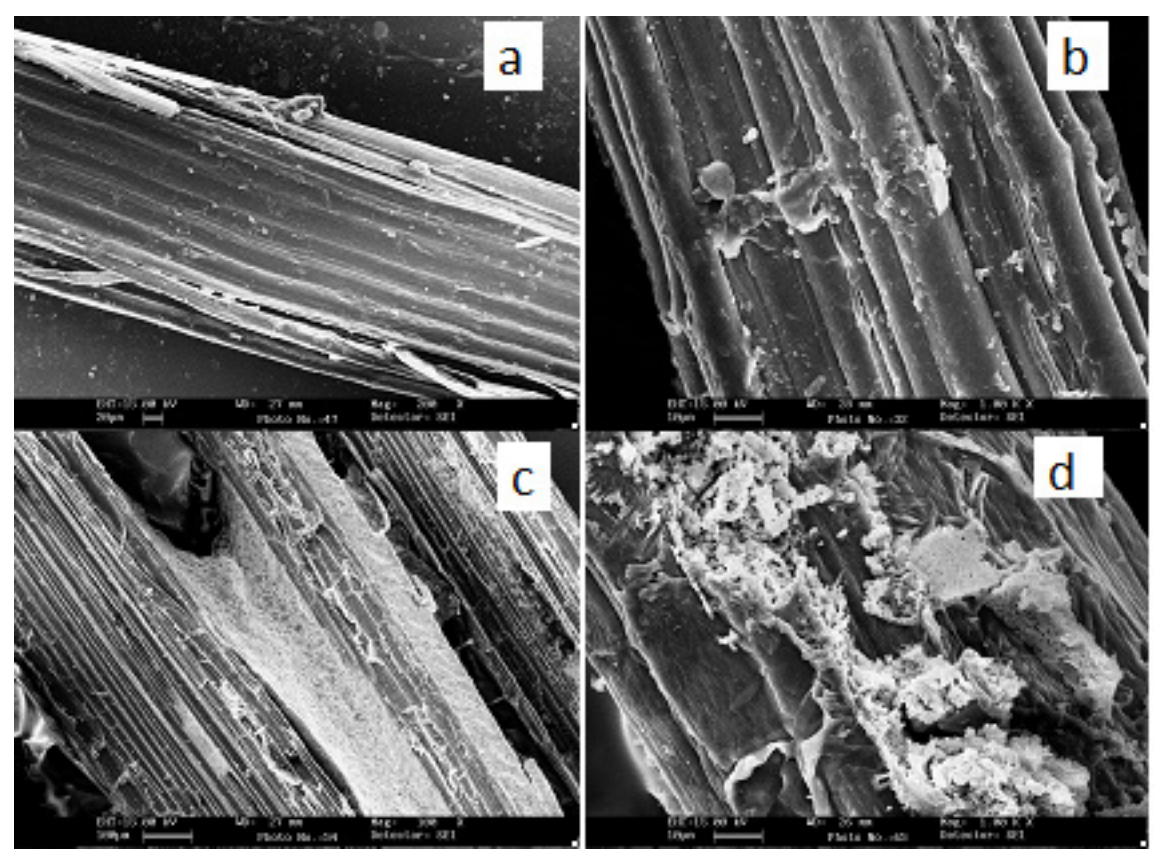

Figure 3. SEM of (a) Raw fiber, (b) Alkali Treated $5 \%$ for $4 \mathrm{hrs}$. (c) Alkali Treat ed $10 \%$ for $4 \mathrm{hrs}$. (d) Alkali Treated $15 \%$ for $4 \mathrm{hrs}$

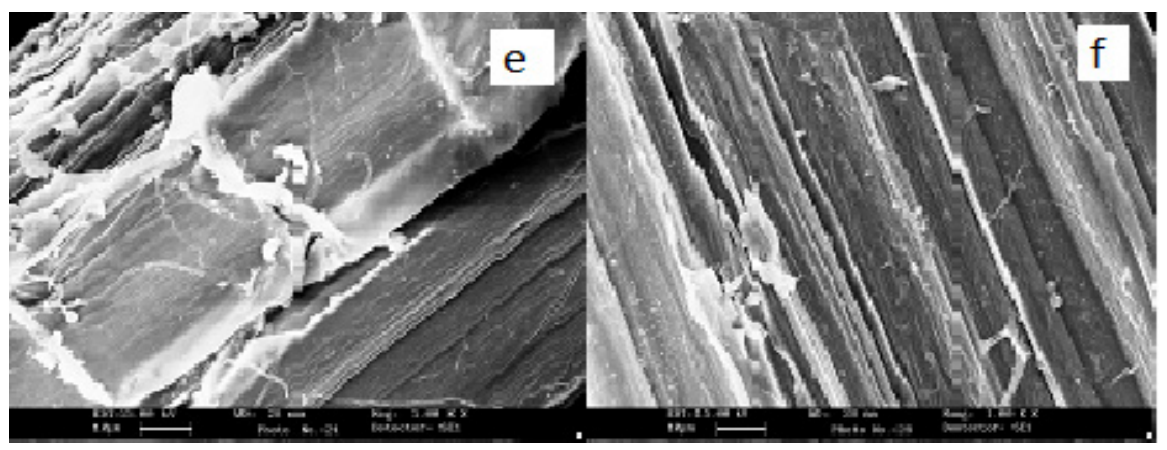

Figure 4. SEM of Benzoyl peroxide Treated (e) 30 minute (f) 45 minute

Table 1. T GA data of raw and chemical treated sisal fibers

\begin{tabular}{|c|c|c|c|c|c|}
\hline S.No. & Sample & IDT $\left({ }^{\circ} \mathrm{C}\right)$ & $\%$ wt. loss & FDT $\left({ }^{\circ} \mathrm{C}\right)$ & $\%$ wt. loss \\
\hline 1 & Raw fiber & 249 & 9.7 & 370 & 70.5 \\
\hline 2 & Alkalitreated Sisal fiber (5\% for 4 hrs.) & 220 & 16.2 & 329 & 55.2 \\
\hline 3 & Alkalitreated Sisal fiber (10\% for 4 hrs.) & 230 & 19.5 & 324 & 53.6 \\
\hline 4 & Alkalitreated Sisal fiber (15\% for 4 hrs.) & 225 & 18.8 & 317 & 53.6 \\
\hline 5 & Benzoyl peroxide treated fiber (30min.) & 250 & 10.1 & 372 & 81.6 \\
\hline 6 & Benzoyl peroxide treated fiber (45min.) & 250 & 16.1 & 350 & 71.4 \\
\hline
\end{tabular}

\section{Results and Discussion}

\subsection{SEM Analysis}

Scanning electron microscopic (SEM) provide an excellent technique for the study of surface morphology of raw and chemically modified sisal fibers. It has been observed that surface of raw sisal fibers differs in smoothness and roughness than chemically treated sisal fibers. These micrographs clearly showed the difference in their surface morphology. The raw fiber (Fig. 3a) surface is very smooth in comparison to treated fibers. Figure $3 b-3 d$ showing mercerized fibers while figure $4 \mathrm{e}-4 \mathrm{f}$ showing $\mathrm{BP}$ treated fibers.

\subsection{Ther mal Analysis (TGA)}

TGA of raw fiber and chemical treated sisal fibers were carried out at a rate of $10^{\circ} \mathrm{C} / \mathrm{min}$ in nitrogen as a function of percentage weight loss versus temperature. The initial and final decomposition temperatures of raw fiber were $249^{\circ} \mathrm{C}$ and $370^{\circ} \mathrm{C}$ respectively with percentage weight loss of $9.7 \%$ and $70.5 \%$ respectively. The IDT for alkali, and benzoyl peroxide treated fibers are $220,230,225,250$ and $250^{\circ} \mathrm{C}$ respectively and final decomposition temperatures are 329 , $324,317,372$ and $350^{\circ} \mathrm{C}$ respectively as shown Table 1.

First stage decomposition is due to primary changes i.e. breakdown of hemicellulose, glycosidic linkage and loss of 
mo isture whereas the second stage of decomposition is due to cellulosic and lignin degradation. It is shown in Figure 5 and 6.

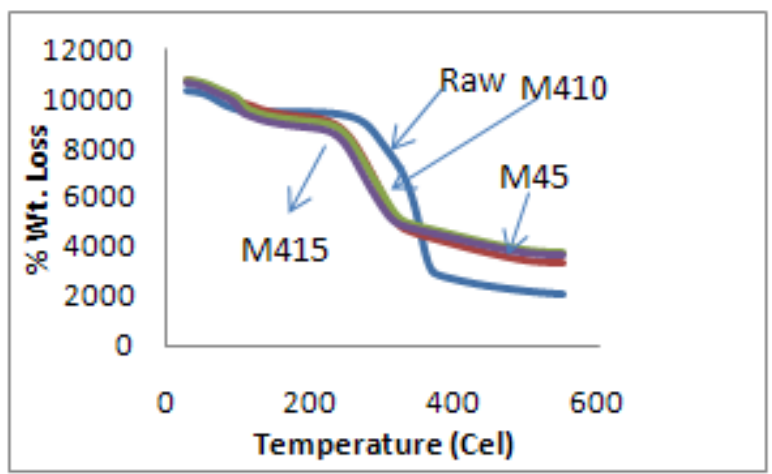

Figure 5. T GA P lot of Raw and Mercerized sisal fibers

Decrease in thermal stability in treated sisal fiber indicate that after che mical treat ments surface of fibers beco me rough and fiber beco me more a mo rphous. The final deco mposition temperature decreases after alkali treatments. The decrease in final stage decomposition temperature indicates that after treatments, there is much loss in cellulosic and lignin degradation as observed by several researchers [6].

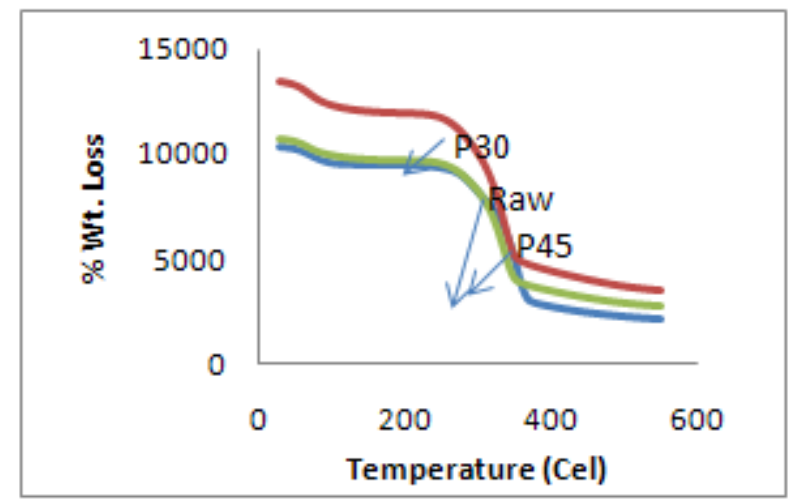

Figure 6. TGA P lot of Raw and Peroxide treated sisal fibers

\subsection{XRD Analysis}

$\mathrm{X}$-ray diffraction studies were performed on X-ray diffractometer. It is evident from Table 2 that raw fiber at $2 \theta$ scale gave peaks at 22.0 and 18.0 with relative intensity is 877 and 346 respectively. Percentage crystallinity $(\% \mathrm{Cr})$ and crystallinity index (C.I.) of raw sisal fiber are 71.7 and 0.60 respectively whereas percentage crystallinity of alkali treated fibers $(5 \%, 10 \%$ and $15 \%$ for $4 \mathrm{Hrs})$ were $74.3,62.0$ and 51.2 Whereas crystallinity index of alkali treated fibers are $0.65,0.40$, and 0.40 respectively and percentage crystallinity of peroxide treated fiber ( 30 and 45 minutes) were 71.0 and 72.0 and crystallinity index were 0.60 and 0.61 respectively.

The counter reading at peak intensity at $22^{\circ}$ is said to represent the crystalline material and the peak intensity at $18^{\circ}$ corresponds to the amorphous material in cellulose [11-12]. Percentage Crystallinity[13] and crystalline index[14-15] were calculated as follow:

$$
\begin{gathered}
C . I .=\frac{I_{22}-I_{18}}{I_{22}} \\
\% C r=\frac{I_{22}}{I_{22}+I_{18}} \times 100
\end{gathered}
$$

Where $I_{22}$ and $I_{18}$ are the crystalline and amorphous intensities at $2 \theta$ scale close to $22^{\circ}$ and $18^{\circ}$, respectively.

\begin{tabular}{|c|c|c|c|c|c|}
\hline S.No. & Sample & $\begin{array}{c}\mathbf{I}_{22} \\
\text { (at } 2 \theta \\
\text { scale) }\end{array}$ & $\begin{array}{c}\mathbf{I}_{18} \\
\text { (at } 2 \theta \\
\text { scale) }\end{array}$ & $\% \mathrm{Cr}$. & C.I. \\
\hline 1 & Raw fiber & 877 & 346 & 71.7 & 0.60 \\
\hline 2 & $\begin{array}{l}\text { Alkalitreated Sisal } \\
\text { fiber ( } 5 \% \text { for } 4 \text { hrs.) }\end{array}$ & 874 & 302 & 74.3 & 0.65 \\
\hline 3 & $\begin{array}{l}\text { Alkalitreated Sisal } \\
\text { fiber }(10 \% \text { for } 4 \mathrm{hrs})\end{array}$ & 683 & 403 & 62.0 & 0.40 \\
\hline 4 & $\begin{array}{l}\text { Alkalitreated Sisal } \\
\text { fiber ( } 15 \% \text { for } 4 \mathrm{hrs} \text { ) }\end{array}$ & 433 & 414 & 51.2 & 0.40 \\
\hline 5 & $\begin{array}{l}\text { Benzoyl peroxide } \\
\text { treated fiber }(30 \mathrm{~min} .)\end{array}$ & 1092 & 430 & 71.0 & 0.60 \\
\hline 6 & $\begin{array}{l}\text { Benzoyl peroxide } \\
\text { treated fiber }(45 \mathrm{~min} .)\end{array}$ & 776 & 301 & 72.0 & 0.61 \\
\hline
\end{tabular}

Table 2. XRD dat a of raw and chemical treat ed sisal fibers

A poor crystallinity index in case of alkali treated sisal fibers means poor order of cellulose crystals to the fiber axis during treatments, indicated by the lower crystallin ity index. Thus clearly indicate that cellulose crystals are better oriented in sisal fibers followed by alkali treated sisal fibers. The graph of raw and chemical treated fiber is shown in figure 7 and 8 .

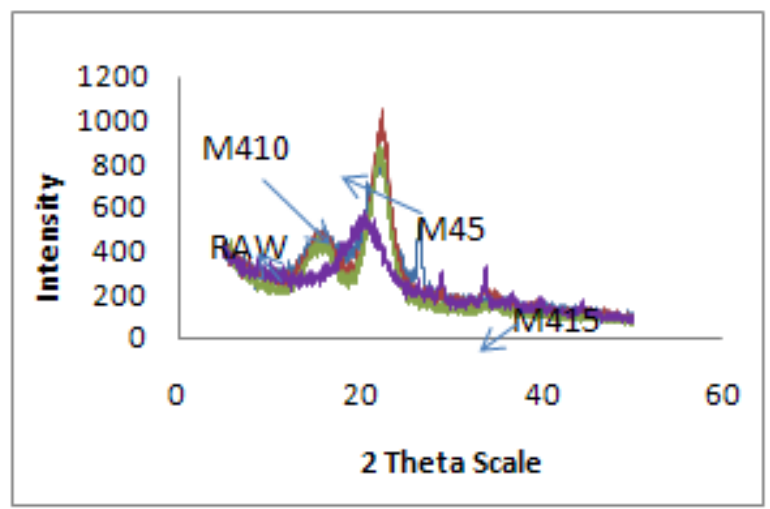

Figure 7. XRDP lot of Raw and Mercerized sisal fibers

$\mathrm{X}$-ray results for peroxide treatments which show an increase in the 'crystallinity' index indicate improvement in the order of the crystallites as the cell wall thickens upon peroxide treatment. These treatments were reported to reduce the proportion of crystalline material present in plant fibers, as observed by several researchers [17-18].

The increase of crystallin ity index in pero xide treated sisal fibers indicated that the chemical treatments induced the crystallinity and it increase due to the removal of a morphous materials like hemicellulose, lignin, and some other 
non-cellulosic material.

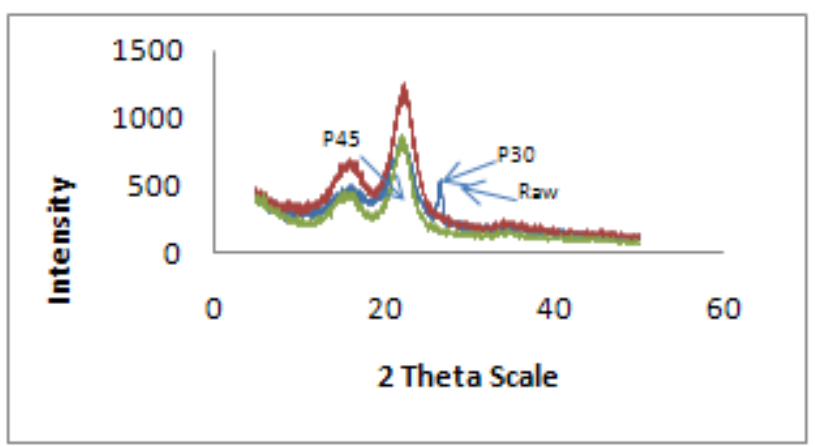

Figure 8. XRDP lot of Raw and Peroxide treated sisal fibers

\section{Conclusions}

It is believed that the increase in the crystallinity index obtained by X-ray diffraction is in actual fact an increase of the order of the crystallite packing rather than in increase in the intrinsic crystallinity. Morphology of sisal fiber was changed by chemical treatments. The surface of sisal fiber becomes rougher after treatments in comparis on with s mooth and clear surface of raw sisal fibers. The removal of surface impurities on plant fibers may be an advantage for fiber to matrix adhesion as it may facilitate both mechanical interlocking and the bonding reaction due to the exposure of the hydroxyl groups to chemicals such as resins and dyes.

\section{ACKNOWLEDGEMENTS}

Authors would like to thanks Institute instrumentation centre, Indian institute technology Roorkee and Singhania university, Rajasthan for providing all the instrumentation facilities and provide results well in time. We would also like to thanks all the faculty members of chemistry research lab, Haryana institute of technology, Haryana for helping us in carried out the whole research works.

\section{REFERENCES}

[1] Kalia, S., Kaith, B.S., Kaur, I., "Pre treatments of natural fibers and their application as reinforcing material in polymer composites-a review", Wiley, Polym. Engg. Sci., 49, 1253-1272, 2009.

[2] Kalia S., Kaushik V.K., Sharma R.K., "Effect of Benzoylation and Graft Copolymerization on Morphology, Thermal Stability, and Cry stallinity of Sisal Fibers" Taylor \& Francis, J. Nat. Fib. 8, 1, 27- 38, 2011.

[3] Li. X., Tabil, L.G., Panigrahi, S., "Chemical treatments of natural fiber for use in natural fiber-reinforced composites: a review", Springer, J. polym. Environ., 15, 25-33, 2007.

[4] Kalia S., Vashistha S., "Surface Modification of Sisal Fibers
(Agave sisalana) Using Bacterial Cellulase and Methyl Methacrylate", Springer, J. Polym. Environ., 20,142-151, 2012.

[5] Calado, V., Barreto, D.W., D'almeida, J.R.M., "The effect of a chemical treatment on the structure and morphology of coir fibers", Springer, J. mat. Sci. lett., 19, 2151-2153, 2000.

[6] Sreekala, M.S., Kumaran, M.G., Joseph, S., Jacob, M., Thomas, S., "Oil palm fibre reinforced phenol formaldehyde composites: influence of fibre surface modifications on the mechanical performance", Springer, Appl. Compos. Mater., 7, 295-329, 2000

[7] Paul, A., Joseph, K., Thomas, S., "Effect of surface treatments on the electrical properties of low-density poly ethy lene composites reinforced with short sisal fibers", Science direct, Compos. Sci. Technol., 57, 67-79, 1997.

[8] Sreekala, M.S., Kumaran, M.G., Thomas, S., "Water sorption in oil palm fiber reinforced phenol formaldehy de composites", Elsevier, Compos. Part A: Appl. Sci. Manuf., 33, 763-777, 2002.

[9] Wang, B., Panigrahi, S., Tabil, L., Crerar, W., "Pre-treatment of flax fibers for use in rotationally molded biocomposites", Sage publication, J. Reinf. Plast. Compos., 26, 447-463, 2007.

[10] Kaith, B.S., Kalia, S., "Synthesis and characterization of graft co-polymers of flax fiber with binary vinyl monomers", Taylor and Francis, Int. J. Polym. Analys. Charact., 12, 401-412, 2007.

[11] Singh, V., Tiwari, A., Tripathi, D. N., Sanghi, R., "Grafting of polyacrylonitrile onto guar gum under microwave irradiation", Wiley, J. Appl.Polym. Sci., 92, 1569 - 1575, 2004.

[12] Singh, V., Tiwari, A., Tripathi, D. N., Sanghi, R.," Microwave promoted synthesis of chitosan-graft-poly (acry lonitrile)", Wiley, J. Appl. Polym. Sci., 95, 820-825, 2004.

[13] Kaith, B. S., Singha, A. S., Gupta, S. K., "Graft copolymerization of Flax fibres with binary vinyl monomer mixtures and evaluation of swelling, moisture absorbance and thermal behaviour of the grafted fibres", A. A. Balkema Publishers J. Polym. Mater., 20, 195 -199, 2003.

[14] Princi, E., Vicini, S., Pedemonte, E., Mulas, A., Franceschi, E., Luciano, G., Trefiletti, V., "Thermal analysis and characterisation of cellulose grafted with acrylic monomers", Elsevier, Thermochim. Acta, 425, 173-179, 2005.

[15] Kaith, B. S., Singha, A. S., Kalia Susheel, "Mechanical Properties of Raw Flax and Flax-g-poly (MMA) Reinforced Phenol-Formaldehyde Composites", Springer, Int. J. Plast. Tech., 10, 572-587, 2006.

[16] Aboul-Fadl, S.M., Zeronian, S.H., Kamal, M.M., Kim, M.S., Ellison, M.S., " Effect of mercerisation on the relation between single fibre mechanical properties and fine structure for different cotton species", SAP, USA, Textile Research Journal, vol. 55, 461 - 469,1985.

[17] Geethamma, V.G., Joseph, R., Thomas, S., "Short Coir fibre Reinforced Natural Rubber Composites: Effects of Fibre

[18] Length, Orientation and Alkali Treatmant", Wiley, J. App. Poly. Sci., vol. 55, 583 - 594, 1995. 